\title{
Analysis on the Characteristics and Cause of a Compound Pollution Process in Changsha in 2017
}

\author{
$H U$ Yan $^{1,2}$, Liu Hongwu ${ }^{1,2^{*}}$, LIU Huanqian ${ }^{3}$, Yin Zhonghai ${ }^{1,2}$ \\ 1Meteorological Observatory of Hunan Province, China \\ 2Hunan Key Laboratory of Meteorological Disaster Prevention and Reduction, China \\ 3Meteorologic technology equip center of Hunan Province, China
}

\begin{abstract}
Using the conventional meteorological observations, the air Air quality monitoring data, the Lband wind-profiling radar data, the NECP reanalysis data, and the simulation results of the HYSPLIT4 model, the compound pollution process from November 2 to 5, 2017 in Changsha is comprehensively analyzed in this study, including the sources and transport paths of pollutions, the Meteorological conditions and atmospheric boundary layer characteristics. The results showed that the process of air pollution in Changsha is a compound pollution process with high concentration of $\mathrm{O}_{3}$ and fine $\mathrm{PM}_{2.5}$ coexisting. It reached serious pollution from 08:00 to $11: 00$ on $4, \mathrm{PM}_{2.5}$ was $269.3 \mathrm{ug} \cdot \mathrm{m}^{-3}$ at 09:00 on 4 November. The characteristics of the two phases of this pollution process were clearly different. The first phase was mainly result of accumulation of local pollutants, and the second one was mainly result of outside resource. The maximum wind were light breezein on this pollution process, gentle breeze mainly occurred in the second stage of pollution, and the maximum wind velocity was $4.4 \mathrm{~m} / \mathrm{s}$. It appearred multi-layer inversion usually, temperature stratification was stabled, and the inversion layer thickness reached the maximum value $909 \mathrm{~m}$ at 20:00 on 3 November. The boundary layer convergenced and ascented movement, horizontal transport, vertical wind field distribution and atmospheric layer provided the favorable conditions for the air pollution process. The results showed that short-range transport of pollutants is the maily reason based on the HYSPLIT4 model, the northeast airflow was dominant at $100-1000 \mathrm{~m}$ height. The vary of wind profile data and $\mathrm{CO}$ and $\mathrm{SO}_{2}$ emission ratio showed that the different pollution characteristics of two phases, the maximum ratio was more than 100. It has an important indicator for weather forecast in Changsha.
\end{abstract}

\section{Introduction}

With the rapid growth of GDP leading by automation industry in the central and eastern regions of China in recent years, heavy pollution processes occurred frequently, and the situation of atmospheric pollution prevention and control is becoming more and more serious[1].The aerosol pollution is seriously in urban agglomerations such as Yangtze River Delta and Pearl River Delta , and haze weather is increasing[2-3].To analyze the relationship between atmospheric quality and meteorological conditions in big and medium-sized cities in China has become an important content of air pollution research[4-6]. Such as Xu Xiang de[7] analyses the characteristics of atmospheric pollution sources in urban communities, shows that the contribution rates of different emission sources causing atmospheric pollution are different in winter and summer. Davis et at [8] found that the large-scale circulation characteristics and local meteorological factors played a decisive role in the heavy pollution process. It shows that the local atmospheric factors and the pollutants of long-distance transportation by straw burning, and causes heavy pollution [9-11]. In addition, with the study of multiple regions found [12- 13]atmospheric quality is closely related to meteorological factors, such as wind, rainfall, relative humidity and temperature have certain influence on the diurnal variation of pollutant concentration.

It was the first heavy pollution process after entering the special protection period during November 2-5, 2017 in Changsha. The primary pollutants are high concentration of ozone and $\mathrm{PM}_{2.5}$, which was 35 days earlier than 2016 and 39 days earlier than 2015. This paper makes a detailed analysis of the composite pollution process from the characteristics of pollutant concentration change and meteorological factors, local source change and external source trace of pollutants, and finds out the reasons for the formation of heavy pollution weather process earlier than the same period in previous years, to provide technical reference for the composite pollution process forecast in the future.

\section{Materials and methods}

Meteorological data are derived from surface and high altitude observation data in Micaps format of China Meteorological Administration, and pollutant concentration data are derived from atmospheric quality

\footnotetext{
* Corresponding author:45877780@qq.com
} 
automatic monitoring station data of Hunan Environmental Monitoring Center.Wind profile data from Changsha Observatory (station number : 57687 , position : $28.10^{\circ} \mathrm{N}, 112.78^{\circ} \mathrm{E}$ ) L band boundary layer wind profile radar data, observation field elevation $119 \mathrm{~m}$. It can provide a set of detection data every 6 minutes. The vertical resolution is $120 \mathrm{~m}$ below $2000 \mathrm{~m}$ and $240 \mathrm{~m}$ above $2000 \mathrm{~m}$. The backward trajectory is calculated using the Global Data Assimilation System (GDAS) data from the National Oceanic and Atmospheric Administration (NOAA). The HYSPLIT4 trajectory model of NOAA is mainly used for trajectory calculation. This model can deal with different types of meteorological fields. It is a hybrid calculation model based on Eulerian and Lagrangian. Because it can calculate different types of emission sources, it is widely used in atmospheric pollutant transport research [14].

\section{The Characteristics of pollution process}

The heavy pollution process occurred in eastern Hunan from November 2 to 5,2017 . Changsha was one of the most polluted areas, and the daily value of AQI was the highest in Hunan.

From figure $1, \mathrm{PM}_{2.5}$ is the primary pollutant in this pollution process, and the average mass concentration has two peaks. According to the concentration change, the pollution process is divided into two stages. The first stage was from 02:00 on 2 to 20:00 on 3 November. AQI reached the level of heavy pollution with consecutive 16 hours in Changsha. $\mathrm{PM}_{2.5}$ reached the first peak at 02:00 on 3 , which was $234.2 \mathrm{ug} \cdot \mathrm{m}^{-3}$. It decreased significantly at $10: 00$ on 3 , and was less than $100 \mathrm{ug} \cdot \mathrm{m}^{-3}$ with consecutive 5 hours. The second stage was from 03:00 on 4 to $02: 00$ on 5 , the heavy pollution concentration was above 18 hours consecutively, reached serious pollution from 08:00 to $11: 00$ on $4, \mathrm{PM}_{2.5}$ was $269.3 \mathrm{ug} \cdot \mathrm{m}^{-3}$ at 09:00 on 4, reached the second peak. It decreased below $100 \mathrm{ug} \cdot \mathrm{m}^{-3}$ at 03:00 on 5 November, and the pollution process ended.

The variation curve of $\mathrm{PM}_{10}$ in this pollution process was similar to that of $\mathrm{PM}_{2.5}$, and there was correlation highly. The $\mathrm{O}_{3}$ concentration reached 2 to 3 pollution levels, showing three peaks. The two turning points of $\mathrm{O}_{3}$ concentration from rising to falling occurred in the first stage of $\mathrm{PM}_{2.5}$ concentration surge stage [15]. Because pollutants can weak visibility and $\mathrm{UV}$ radiation, $\mathrm{O}_{3}$ concentration began to decline, indicating that the early stage of the pollution process was a typic al compound pollution. The curve of $\mathrm{CO}$ concentration is similar to $\mathrm{PM}_{2.5}$ and has highly correlation. $\mathrm{NO}_{2}$ and $\mathrm{SO}_{2}$ reached concentrations peak only one time, which occurred before the peak of $\mathrm{PM}_{2.5}$.

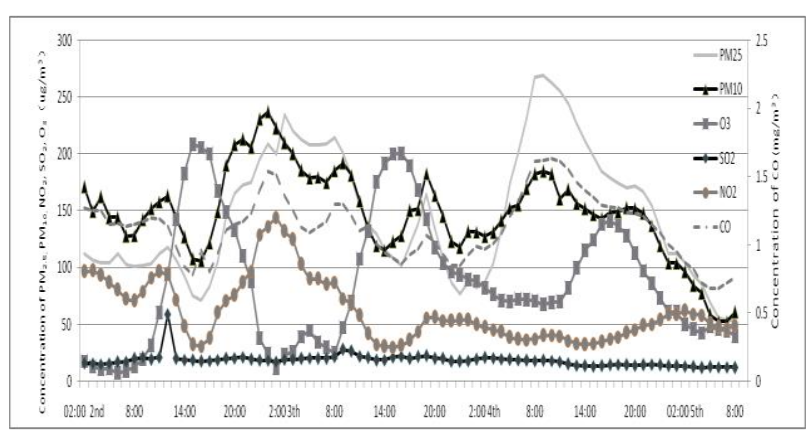

Fig. 1. Changes in concentrations of $\mathrm{PM}_{2.5}$ and other pollutants in Changsha from 02:00 on 2 to 08:00 on 5 November

\section{Analysis on formation mechanism of pollution process}

\subsection{Circulation background}

The weather situation determines the distribution and distribution of meteorological elements macroscopically change, affect the stability of the atmosphere[16]. The compound pollution process occurred earlier in Changsha, had different pollution characteristics at different stages. The analysis of circulation background shows that the meridional circulation is dominant in themiddle and high latitudes on $500 \mathrm{hPa}$ before pollution. The blocking high over the Ural Mountains was established on 31 October and maintained for more than 3 days, with branches and junctions exceeding 30-40 longitudes. Transverse trough was from River oxbow to Northeast China, and the South of the Changjiang River is uniform pressure field at 08:00 on 2 November. The blocking high over the Ural Mountains collapsed, transverse trough turned to vertical, the southerly cold air was guided by northeast cold vortex at 08:00 on 3 November. The center of ground cold high pressure reached $1037.5 \mathrm{hPa}$, cold air moved southward by the northward path, pressure gradient increased significantly. The cold air arrived quickly crossing nanling moutains to northern of Guangdong and Guangxi in the evening on 3 November, the moving speed was over 10 latitudes one day. The cold air maily moved southward, sea level pressure rised rapidly. Pollutants of upstream area tramsmitted to changsha by cold air. On 5 th, the northward wind strengthened the horizontal diffusion of pollutants and damaged the stable stratification, the pollution process ended (figure not shown).

\subsection{Meteorological characteristics analysis of combined pollution process}

\subsubsection{Visibility and relative humidity}

The correlation coefficient between $\mathrm{AQI}$ and $\mathrm{PM}_{2.5}$ was 0.996 in this pollution process, showing a significant positive correlation and consistent variation trend. Therefore, the $\mathrm{PM}_{2.5}$ concentration of the primary pollutant was selected to analyze its correlation with 
meteorological factors. First, comparing and analyzing the variation trends of visibility and relative humidity with $\mathrm{PM}_{2.5}$ concentration (figure not shown). In the first stage, the correlation coefficient between $\mathrm{PM}_{2.5}$ and visibility was 0.2 , showing a weak positive correlation, which was different from the high positive correlation between $\mathrm{PM}_{2.5}$ and visibility in many typical heavy pollution processes. In the second stage, the correlation coefficient between $\mathrm{PM}_{2.5}$ and visibility was -0.64 , showing a significant negative correlation. In the first stage, with the emergence of the first peak of $\mathrm{PM}_{2.5}$, the peak of visibility (VV>10km) appeared subsequently. It showed that before the advent of cold air, the ground temperature increased, and the solar radiation increased, which increased the concentration of $\mathrm{O}_{3}$, thus showing the characteristics of compound pollution.

In the second stage, visibility was low. When the concentration of $\mathrm{PM}_{2.5}$ reached serious pollution, visibility is less than $5 \mathrm{~km}$. The suspension of fine particles reduced visibility, and its pollution characteristics conformed to the characteristics of typical heavy pollution processes.

The correlation coefficient between $\mathrm{PM}_{2.5}$ and relative humidity was 0.21 in the two stages of the pollution process, showing a positive correlation. The hygroscopic increase of pollutants was clearly. High relative humidity is conducive to the secondary transformation of gaseous pollutants to particulate pollutants [17]. The peak of relative humidity was ahead of the two peaks of $\mathrm{PM}_{2.5}$, indicating that Baik pointed the water-soluble compounds in $\mathrm{PM}_{2.5}$ had high hygroscopicity [18], and their content and particle size would increase with the increase of relative humidity.

\subsubsection{Horizontal winds}

The near-surface wind field determined the horizontal diffusion capacity of pollutants in the boundary layer, and the wind direction and frequency affected the transmission direction and diffusion pathes of pollutants. From the analysis by Fig.2 (a), it showed that the the maximum wind were light breezein this pollution process, accounting for $60.7 \%$ at $1.6-3.3 \mathrm{~m} / \mathrm{s}$, accounting for $22.8 \%$ at $0.3-1.5 \mathrm{~m} / \mathrm{s}$ (light air), $16.5 \%$ at $3.4-5.4 \mathrm{~m} / \mathrm{s}$ (gentle breeze). Smaller near-surface wind velocity was not conducive to the diffusion and transport of pollutants, so that the concentration maintained a high level. Gentle breeze mainly occurred in the second stage of pollution, and the maximum wind velocity was $4.4 \mathrm{~m} / \mathrm{s}$. From the analysis by Fig.2 (b), it showed that the dominant wind direction was NNW in Changsha, accounting for $25.3 \%$, accounting for $16.4 \%$ at $\mathrm{N}$, and there was no southerly wind direction during the pollution period. It showed that the transmission characteristics of the pollution process were obviously. In the second stage, when the main body of cold air was southward, the topography of three mountains and northward openings was conducive to the rapid transportation of pollutants in the upper reaches of the northerly wind direction in Hunan. Changsha is located in the eastern plain of Hunan. After the establishment of the transmission path, the concentration of $\mathrm{PM}_{2.5}$ pollutants had increased to more than $300 \mathrm{ug} \cdot \mathrm{m}^{-3}$, then there was a heavy pollution peak.

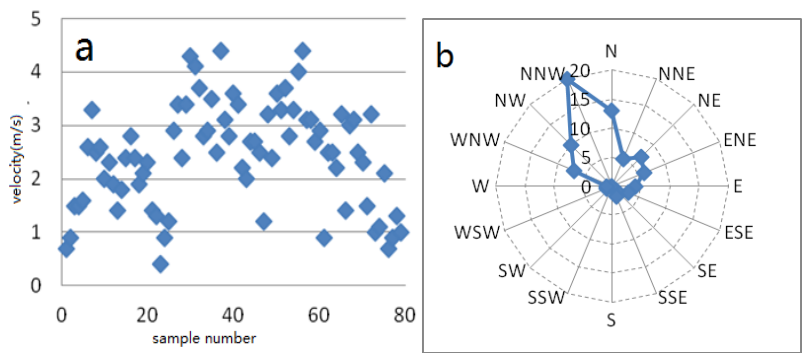

Fig. 2. Wind velocity scatter plots(a) and wind direction rose map (b) in Changsha from 02:00 on 2 to 08:00 on 5 November

\subsubsection{Dynamic mechanism}

Analyzing the vertical velocity of heavy pollution period, sinking motion was dominated in the first stage of heavy pollution. The sinking temperature increased the concentration of $\mathrm{O}_{3}$ on the one hand, and the pollutants accumulated in the boundary layer on the other hand. By 14:00 on 3 th November, a negative velocity center appeared near the ground below $1000 \mathrm{~m}$, and there was a weak convergence ascending motion. Due to the small wind speed, the pollutants gradually accumulated. Until to $4: 20$ (Fig. 3), the vertical velocity center expanded to more than $1500 \mathrm{~m}$, the atmospheric turbulence movement strengthened, the upper and lower exchange capacity strengthened, and the pollutants gradually diffused and diluted.
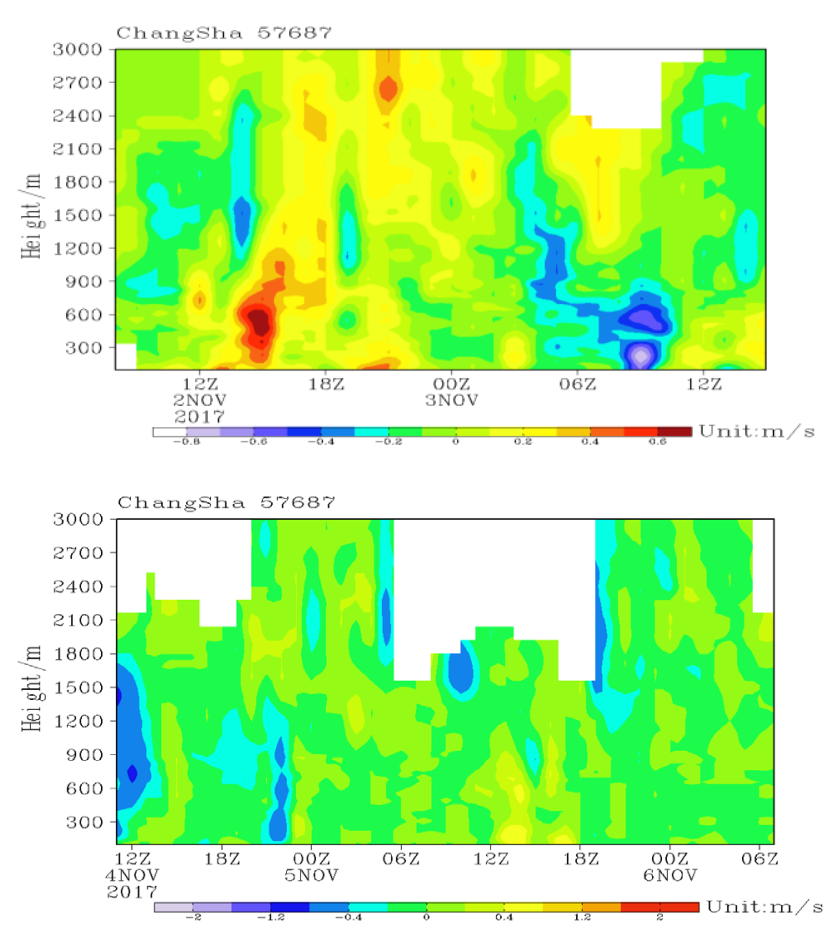

Fig. 3. Vertical velocity height-time sequence diagram in Changsha (a: from 16:00 on 2 to 23:00 on 3 November, b:from 18:00 on 4 to $16: 00$ on 6 November,) 


\subsubsection{Thermodynamics mechanism}

Usually the inversion in the atmospheric boundary layer had a great influence on the diffusion of near-surface pollutants [19]. The warm and dry cover wasn't conducive to the turbulent motion and heat transfer in the vertical direction of the atmosphere. When the inversion was generated, the turbulent motion was suppressed and the atmospheric diffusion ability was weakened. Grounding inversion layer usually had an inhibitory effect on air convection, which was conducive to the emergence of haze weather [20].

Table 1. Table of inverse Temperature Indicators for Changsha from 02:00 on 2 to 20:00 on 4 November

\begin{tabular}{|l|c|c|c|c|c|c|}
\hline & 0208 & 0220 & 0308 & 0320 & 0408 & 0420 \\
\hline $\begin{array}{l}\text { multiple } \\
\text { layer } \\
\text { inversion }\end{array}$ & Yes & - & Yes & & Yes & Yes \\
\hline $\begin{array}{l}\text { inversion } \\
\text { thickness }\end{array}$ & 339 & 117 & 144 & 909 & 675 & 198 \\
\hline $\begin{array}{l}\text { inversion } \\
\text { intensity }\end{array}$ & 1.76 & 0 & 2.08 & 0.44 & 0.14 & 2.52 \\
\hline $\begin{array}{l}\text { top height } \\
\text { of ground } \\
\text { inversion }\end{array}$ & 345 & 120 & 120 & - & - & - \\
\hline
\end{tabular}

The effects of inversion layer thickness, inversion layer bottom and inversion intensity variation trend on pollution process were selected. In this paper, the inversion below $500 \mathrm{~m}$ was defined as the ground inversion. The thickness of the inversion layer was the height difference between the two inversion layers. The thickness formula: $\mathrm{Th}=\mathrm{H} 1-\mathrm{H} 2$. The intensity of the inversion layer referred to the change of temperature with the height increasing by $100 \mathrm{~m}$. From 20:00 on 2 to $08: 00$ on 5 , the distribution charactics of inversion layer were less cloudy in the morning of 2 nd, the surface radiation cooling was obvious in Changsha, the thickness of inversion layer increased and the intensity strengthened, and weakened at 08:00 on 3, and reached the maximum value $909 \mathrm{~m}$ at 20:00 on 3 November (Table. 1 ). On the first stage, the concentration of $\mathrm{PM}_{2.5}$ increased sharply to more than $230 \mathrm{ug} \cdot \mathrm{m}^{-3}$ at $02: 00$ on 3 November, and the first heavy pollution peak appeared below $100 \mathrm{~m}$. The inversion thickness was $144 \mathrm{~m}$, and the inversion intensity was $2.08{ }^{\circ} \mathrm{C} / 100 \mathrm{~m}$, indicating that the thicker the inversion thickness was, the stronger the intensity was, and the higher the pollutant concentration was. The minimum inversion layer height was below $120 \mathrm{~m}$, most times below $1000 \mathrm{~m}$, which was very conducive to the accumulation of pollutants near the ground. In the second stage, the duration of heavy pollution was longer and the mass concentration was higher. The $\mathrm{PM}_{2.5}$ concentration exceeded $250 \mathrm{ug} \cdot \mathrm{m}^{-3}$ for four consecutive times from 08:00 to 11:00 on 4 November. The process of heavy pollution appearred multi-layer inversion usually, temperature stratification was stable, vertical diffusion movement was blocked, conducive to the accumulation of pollutants. When cold air affected Changsha, the ground inversion disappeared.

\section{The analysis of pollutants Source}

\subsection{Vertical wind profile}

Analyzing the vertical wind profile of the first stage of the pollution process (Fig 4), there was an inclined weak wind speed zone between $300-900 \mathrm{~m}$ from 02:00 to 10:00 on 3 , and the wind velocity was between $0-2 \mathrm{~m} / \mathrm{s}$, indicating that there was a significant conversion zone of wind direction, when the cold air front arrived, and the concentration of $\mathrm{PM}_{2.5}$ appeared the first peak. It showed that the near-surface weak breeze before the cold air front was not conducive to the diffusion of pollutants in the early hygroscopic growth, which aggravated air pollution. After 10:00 the wind velocity increased,through all of layeres, was between $6-8 \mathrm{~m} / \mathrm{s}$ below $1000 \mathrm{~m}$, and turned to a significant northeasterly wind, which was conducive to the transport of pollutants in the upstream region with the northeasterly airflow. From 20:00 on 4, as the wind direction below $1000 \mathrm{~m}$ changed from northeast to northwest wind, the wind direction obviously rotated counterclockwise with the height, and the cold advection quickly descended. The ground wind increased to about 8 $\mathrm{m} / \mathrm{s}$, and the $\mathrm{PM}_{2.5}$ concentration decreased significantly, and the pollution process tended to end. It showed that external sources were important in heavy pollution weather in Changsha.
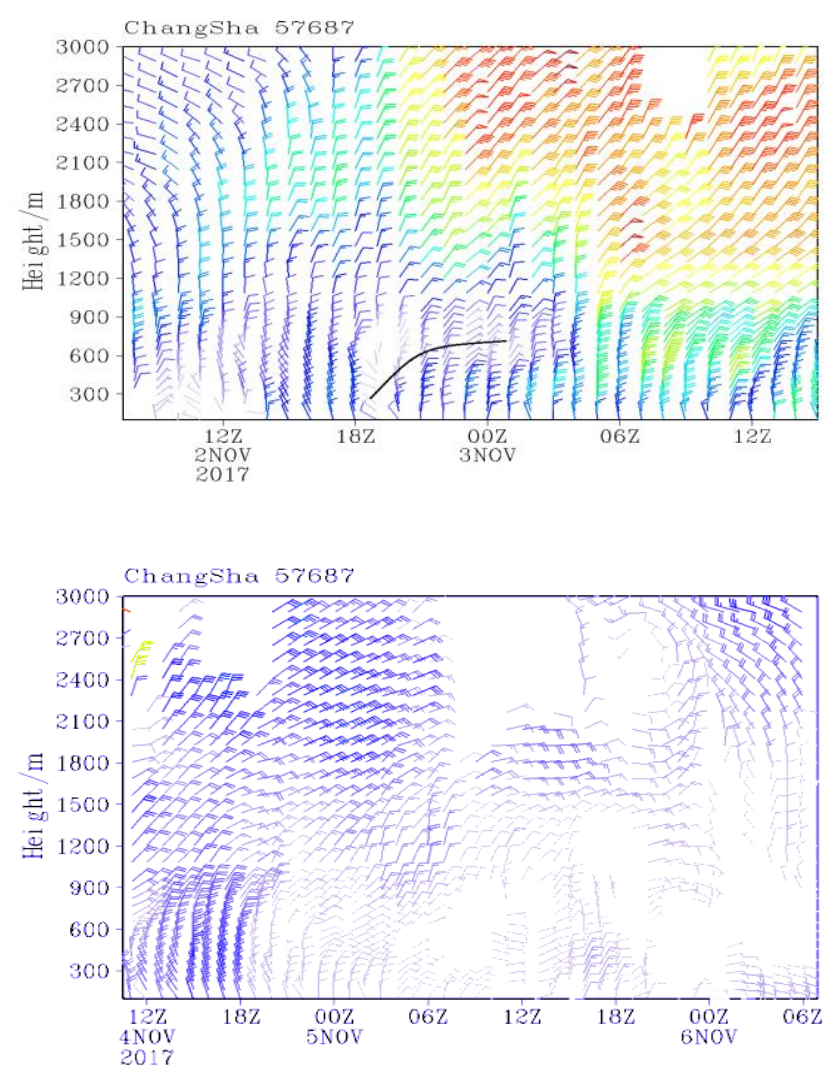

Fig. 4. Time-height sequence diagram of wind profile in Changsha ( a, from $16: 00$ on 2 to $23: 00$ on 3 ; b: 18:00 on 4 to 16:00 on 6 November ) 


\subsection{Emission changes of pollutants}

In a special period, the contribution of urban sources to atmospheric particulate matter and gaseous pollutants were relatively stable. For urban atmospheric pollution sources, the emission charactics of $\mathrm{PM}_{2.5}, \mathrm{CO}$ and $\mathrm{SO}_{2}$ were similar, and their concentrations were significantly positively correlated. The change of $\mathrm{CO}$ and $\mathrm{SO}_{2}$ concentration was very sensitive to straw burning, $\mathrm{CO} / \mathrm{SO}_{2}$ ratio was used to reflect the pollution of straw combustion. There were two peaks of $\mathrm{CO} / \mathrm{SO}_{2}$ ratio in this combined pollution process (Fig. 5). Especially in the second stage, it began to gradually climb from 02:00 on 4 November, and there was an upward period of more than 10 hours, with the maximum ratio of more than 100 . Combining with the fire data of Hunan, there were fires in the central and eastern regions, indicating that the local straw burning pollutants were an important reason for the aggravation of air pollution in this stage.

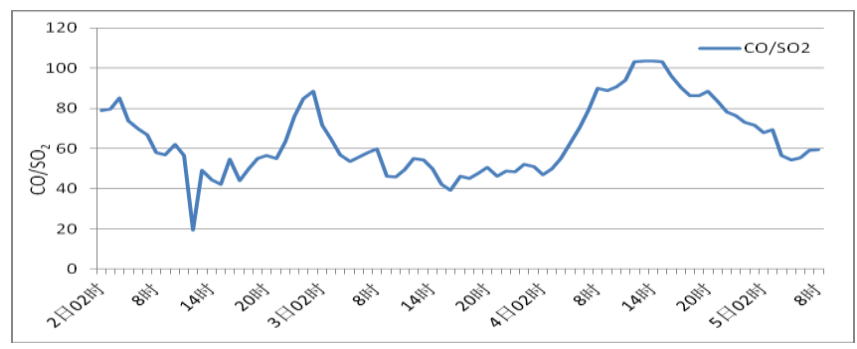

Fig. 5. Variation curve of $\mathrm{CO} / \mathrm{SO}_{2}$ ratio in Changsha

\subsection{The analysis of backward trajectory}

The transportation of exogenous pollution plays a decisive role in the pollution process [21]. The backward trajectory model (HYSPLIT4) was used to analyze the pollutant source and transportation trajectory of the compound pollution process in Changsha. Simulating the backward airflow trajectory of $48 \mathrm{~h}$ at $02: 00$ on 3 and 08:00 on 4 November (Fig. 6), showed that the northeast airflow was dominant at $100-1000 \mathrm{~m}$ height, and the air mass basically did not decrease at $1000 \mathrm{~m}$, while the air mass originated in Wuhan at $500 \mathrm{~m}$ and $100 \mathrm{~m}$. The first peak of AQI reached 203 at 10:00 and the second peak reached 270 at 22:00 on 3 November, two pollution peaks followed in Changsha. The $500 \mathrm{~m}$ and $100 \mathrm{~m}$ backward trajectories showed that the air mass had been moving near the ground, and the pollutants carried from Wuhan had a direct impact on Changsha. It showed that this pollution process was an atmospheric pollution process dominated by ultra-short-range exogenous input and superimposed by pollutants such as local straw combustion.
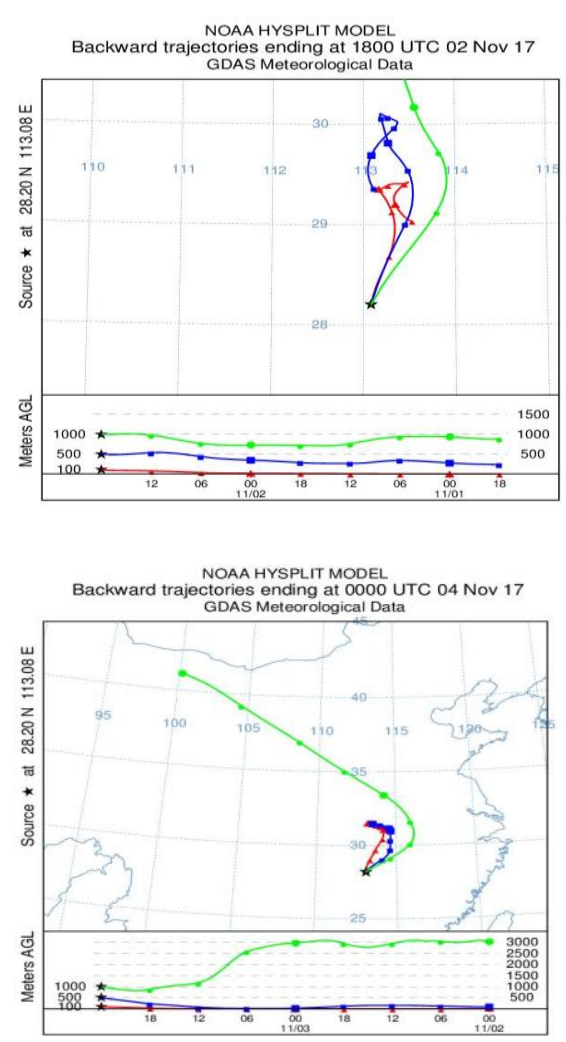

Fig. 6. $48 \mathrm{~h}$ backward trajectory simulation in Changsha ( a, 02:00 on 3 November; b, 08:00 on 4 November)

\section{Conclusions and discussion}

1. The air pollution process in Changsha was a complex pollution process. In the first stage, the peak concentration of pollutants was mainly affected by local pollutant agglomeration and moisture absorption growth. In the second stage, the severe pollution was mainly dominated by the southward transmission of northern cold air. It reached serious pollution from $08: 00$ to $11: 00$ on 4, $\mathrm{PM}_{2.5}$ was $269.3 \mathrm{ug} \cdot \mathrm{m}^{-3}$ at 09:00 on 4 November.

2. The charactics of the first stage of pollution was compound pollution, and the charactics of the second stage was typical pollution. Many pollutants were accumulated locally through weak subsidence and convergence upward movement in the middle and low altitudes of this pollution process, and they were mainly affected by upstream transmission and transported to Changsha in the later stage.

3. In the process of pollution, there was a continuous occurrence of thick inversion on the ground, which caused the accumulation of pollutant particles and the diffusion ability of air pollution decreased significantly. There a multi-period and multi-layer inversion, and there was a stable temperature stratification, which blocked the vertical diffusion movement and aggravated the air pollution situation. Therefore, the application of inverse temperature indicators had a good effect on the thermal condition diagnosis of pollutant accumulation.

4. The weak wind velocity band in the boundary layer indicated that there was a significant conversion band of wind direction, which was conducive to the local 
accumulation of pollutants. When the wind velocity increased and the turbulent diffusion ability strengthened, the pollutants gradually dissipated. The maximum wind were light breezein on this pollution process, gentle breeze mainly occurred in the second stage of pollution, and the maximum wind velocity was $4.4 \mathrm{~m} / \mathrm{s}$. It appearred multi-layer inversion usually, temperature stratification was stabled, and the inversion layer thickness reached the maximum value $909 \mathrm{~m}$ at 20:00 on 3 November. The change of $\mathrm{CO} / \mathrm{SO}_{2}$ ratio reflected how is the straw burning, which can be used as a direct reference index for environmental prediction, the maximum ratio was more than 100 .

5. Analyzing backward trajectory, showed that the shortrange transport of pollutants from the upstream region was very important in this compound pollution process of Changsha, the northeast airflow was dominant at $100-1000 \mathrm{~m}$ height.

Funded projects : Hunan meteorological bureau project in 2021, China Meteorological Administration weather forecaster project (CMAYBY2020-088、CMAYBY2019-076)

\section{References}

1. Ren Z H,Wan B T, Su F Q, et al. Several Characteristics of Atmospheric Environmental Quality in China at Present[J]. Research of Environmental Sciences, 2004, 17( 1) : 1-6.

2. Xu J, Zhang Y H, Fu J S, et al. Process analysis of typical summer time ozone episodes over the Beijing area[J]. Science of the Total Environment, 2008, 399(1-3) : 147-157.

3. An X, Zhu T, Wang Z, et al. A modeling analysis of a heavy air pollution episode occurred in Beijing $[\mathrm{J}]$. Atmospheric Chemistry and Physics, 2007, 7: 31033114.

4. Yu P, Wang J H, Guo S R, et al. Statistical Relation and Diagnostic Foundation Between the Concentration of Majorair Pollutants and Wind Speed[J]. Journal of Qingdao University(Engineering \& Technology Edition), 2000, 15(2) : 72-74.

5. Han X, Wei W S, Liu X C, et al. Characteristic of the Concentration and Distribution of $\mathrm{PM}_{10}, \mathrm{PM}_{2.5}$ and $\mathrm{PM}_{1.0}$ in Urumqi[J]. Desert and Oasis Meteorology, $2015,9$ ( 1$): 32-38$.

6. Zhang J Z, Sun J, Wang G L, et al. Relation Between the Spatial-temporal Distribution Characteristics of Air Quality Index and Meteorological Conditions in Beijing[J]. Meteorological and Environmental Sciences, 2014, 37(1) : 33 -39.

7. Xu X D, Zhou X J, Shi X H, Spatial Structure and Scale Characteristics of Atmospheric Pollution Sources in Urban Communities[J]. Science in China (Series D) , 2005, 35 (addition I ): 1-19

8. Davis R E, Kalkstein L S. Using a spatial synoptic climatological classification to assess changes in atmospheric pollution concentrations[J]. Physical Geography, 1990, 11(4) : 320-342.
9. Fu X, Wang S X, Cheng Z, et al. Source, transport and impacts of a heavy dust event in the Yangtze $R$ iver Delta, China, in 2011[J]. Atmospheric Chemistry and Physics, 2014, 14: 1239-1254.

10. Zhu B, Su J F, Han Z W, et al. Analysis of a serious air pollution event resulting from crop residue burning over Nanjing and surrounding regions[J]. China Environmental Science, 2010, 30(5):585592.

11. Hong Y, Ma Y J, Wang X Q, et al. External Influences in the Haze Episode in The Central City Group of Liaoning: A Case Study[J]. Acta Scientiae Circumstantiae, 2013, 33 (8):2115-2122.

12. Qi D L, Zhang J K, Li X D, et al. Characteristics of air quality and its relationship with meteorological factors from 2001 to 2011 in Xining[J]. Journal of Meteorology and Environment, 2014, 30(2) :51-59.

13. Yan X Y, Gou X H, Liu Y L, et al. Characteristics of concentration of air pollutant and its relationship with meteorological conditions in Yinchuan[J]. Journal of Meteorology and Environment, 2015, 31(2) :21-30.

14. Cao Y, Ma J H, Xu J M, et al. Analysis of a typical air pollution event in Shanghai[J]. Journal of Meteorology and Environment, 2016, 32(1):16-24.

15. Li T T, Wei P, Cheng S Y, et al. Analysis of a Near Earth Surface $\mathrm{O}_{3}$ and $\mathrm{PM}_{2.5}$ Pollution in Combination With its Contaminating Process in Beijing[J]. Journal of Safety and Environment, 2017, 17(5) :1979-1985.

16. Cheng Y F, Hou X W, Zhu B, et al. 2020. The meteorological causes of a heavy pollution process in BTH and YRD area with stable weather condition [J]. Acta Scientiae Circumstantiae, 40(5) : 1575-1586.

17. Zhang G L, Zhen X R, Tan J G, et al. The Analysis of the Relationship Between the Air Quality in Shanghai and Surface Pressure Patterns and Meteorological Factors[J]. Journal of Tropical Meteorology, 2010, 26(1) :124-128.

18. Baik NJ, Kim YP, Moon KC, Visibility study in seoul, 1993[J]. Atmospheric Environment, 1996, 30(13) :2319-2328.

19. Liu C L, Chang Y J, Analysis of Pollution Meteorological Characteristics in Bayuquan[J]. Journal of Meteorology and Environment, 2006, 22(1) :29-33

20. Cao Y, Ma J H, Xu J M, et al. Analysis Of a Typical Air Pollution Event In Shanghai[J]. Journal of Meteorology and Environment, 2016, 32(1) :16-24.

21. Fu C B, Dan L, Tang J X, et al.2020.Analysis of air polluted transportation and potential source in Haikou City based on trajectory model[J]. Acta Scientiae Circumstantiae, 40(1) : 36-42. 